\title{
Association of Maternal and Neonatal Risk Factors with Early Onset Neonatal Sepsis
}

Dr. Debabrata Roy ${ }^{1 *}$, Professor Dr. M.A Mannan ${ }^{2}$, Dr. A.S.M Selim ${ }^{3}$, Dr. Debashish Saha ${ }^{4}$, Dr. Sarbari Saha ${ }^{5}$, Dr. Farhana Afroj ${ }^{6}$

\author{
${ }^{1}$ Junior Consultant, Department of Pediatrics, Upazila Health Complex, Kaliakoir, Gazipur, Bangladesh \\ ${ }^{2}$ Professor, Department of Neonatology, Bangabandhu Sheikh Mujib Medical University (BSMMU), Dhaka, Bangladesh \\ ${ }^{3}$ Assistant Professor Department of Pediatrics, TMSS Medical College Hospital, Bogura, Bangladesh \\ ${ }^{4}$ Consultant, Department of Neonatology, Bangabandhu Sheikh Mujib Medical University (BSMMU), Dhaka, Bangladesh \\ ${ }^{5}$ Medical Officer, Department of Neonatology, Bangabandhu Sheikh Mujib Medical University (BSMMU), Dhaka, Bangladesh \\ ${ }^{6}$ Assistant Professor, Department of Pediatrics, Kumudini Medical College Hospital, Tangail, Bangladesh
}

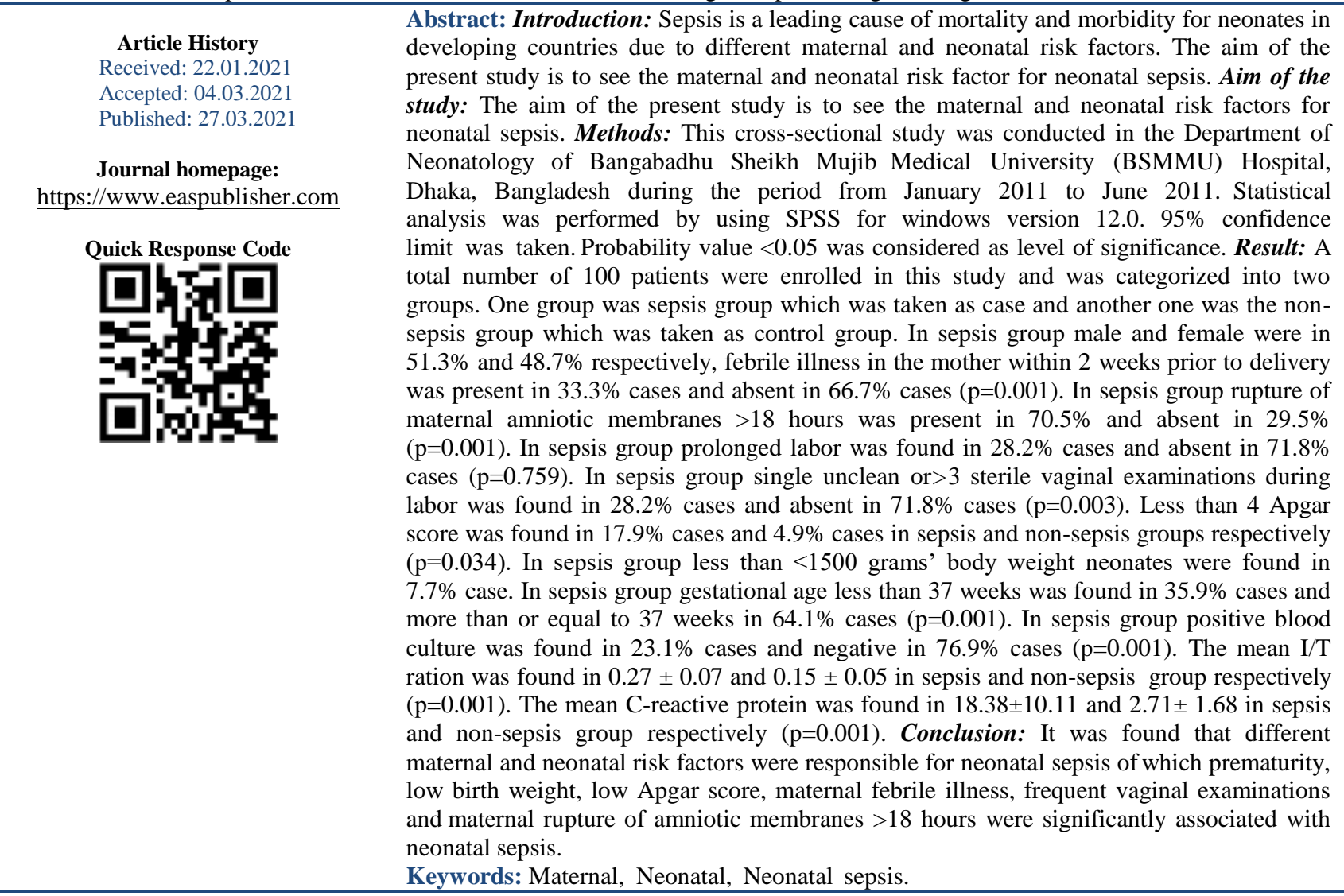

Copyright () 2021 The Author(s): This is an open-access article distributed under the terms of the Creative Commons Attribution 4.0 International License (CC BY-NC 4.0) which permits unrestricted use, distribution, and reproduction in any medium for non-commercial use provided the original author and source are credited.

\section{INTRODUCTION}

Neonatal sepsis is the commonest cause of neonatal mortality ${ }^{1}$. In the pre-antibiotic era neonatal sepsis was usually fatal. It has been classified as either early onset sepsis (EOS) which is at 0-7 day of age or late onset sepsis (LOS) which is 7-28 days of age [2]. It is responsible for $30-50 \%$ of total neonatal deaths each year in developing countries [3]. It is estimated that up to $20 \%$ of neonates develop sepsis and approximately $1 \%$ die of sepsis related causes [4]. As per National
Neonatal Perinatal Database (NNPD) 2002-2003, the incidence of systemic infection is $3 \%$ among intramural babies in tertiary care institutions in India, with septicemia being present in three fourth of the cases and pneumonia in one fourth of neonates [1]. It's most clinical manifestations are meningitis (30-40\%), bacteraemia (40\%), septic arthritis (5\% to $10 \%$ ) and more rarely omphalitis and osteomyelitis and the reported incidence of neonatal sepsis varies from 7 to 38 per 1000 live births in Asia [5], from 6.5 to 23 per 1000 live births in Africa [6], and from 3.5 to 8.9 per 
1000 live births in South America and the Caribbean [7]. By comparison, rates reported in the United States and Australasia range from 6-9 per 1000 live birth [8] and in Europe 0.3-3 per 1000 live births [9]. Infections are one of the commonest causes of neonatal deaths globally. Neonatal sepsis contributes $1 / 3$ neonatal deaths of Bangladesh [10]. Clinical features of sepsis are non-specific in neonates and often overlooked and a high index of suspicion is required for timely diagnosis. It is desirable to administer appropriate therapy as early as possible to the suspected infected infant. In a developing country like Bangladesh, where $80 \%$ delivery occurs at home by unskilled birth attendance as well as proper laboratory facilities are not available at upazilla and district level, identification of risk factors and early initiation of antibiotic therapy can improve the mortality and morbidity. This purpose of the present study is to find out the association between maternal and neonatal risk factors with early onset neonatal sepsis.

\section{OBJECTIVES}

a) General objective

- To see the maternal and neonatal risk factors for neonatal sepsis.

\section{b) Specific Objectives}

- To find out the association of maternal risk factors with neonatal sepsis.

- To find out the association of neonatal risk factors with neonatal sepsis

\section{Methodology \& Materials}

It was a cross sectional study. The study was carried out in the Department of Neonatology at Bangabandhu Sheikh Mujib Medical University (BSMMU), Dhaka. This study was conducted from January 2011 to June 2011 for a period of six (06) months. All the neonate within the age of 72 hours presented with mentioned risk factors in Department of Neonatology at BSMMU were enrolled as study population. The patients were voluntarily included in the study with their consent and they were neither supported nor additionally burdened financially. The sampling technique was consecutive sampling and this purposive sampling technique was used as per inclusions and exclusion criteria. All data were recorded systematically in preformed data collection form (questionnaire) and quantitative data was expressed as mean and standard deviation and qualitative data was expressed as frequency distribution and percentage. Statistical analysis was performed by using MS-Excel$2016 \&$ SPSS for windows version 12.0. $95 \%$ confidence limit was taken. Probability value $<0.05$ was considered as level of significance.

\section{RESULT}

A total number of 100 patients were enrolled in this study and was categorized into two groups. One was sepsis group which was taken as case and another group was the non-sepsis group which was taken as control. Among 39 patients in sepsis group gestational age less than 37 weeks was found in 14 (35.9\%) cases and more than or equal to 37 weeks in $25(64.1 \%)$ cases. Among 61 patients in non-sepsis group gestational age less than 37 weeks was found in 8 $(13.1 \%)$ cases and more than or equal to 37 weeks in 53 $(86.9 \%)$ cases. The difference was statistically significant $(\mathrm{p}=0.001)$ [Table-1]. In sepsis group male and female were in $20(51.3 \%)$ cases and 19 (48.7\%) cases respectively. In non-sepsis group male and female were in $42(68.9 \%)$ cases and $19(31.1 \%)$ cases respectively. The difference was statistically significant $(\mathrm{p}=0.013)$ [Table-2]. Less than 4 Apgar score was found in $7(17.9 \%)$ cases and $3(4.9 \%)$ cases in sepsis and non-sepsis groups respectively. More than or equal to 4 Apgar score was found in $32(82.1 \%)$ cases and 58 $(95.1 \%)$ cases in sepsis and non-sepsis groups respectively. The difference was statistically significant $(p=0.034)$ [Table-3]. In sepsis group less than $<1500$ grams' body weight neonates were found in $3(7.7 \%)$ case, $1500-<2500$ grams' body weight neonates were found in $16(41.0 \%)$ and more than or equal to 2500 grams' body weight neonates were found in $20(51.3 \%)$ cases. In non-sepsis group less than $<1500$ grams' body weight neonates were found in $1(1.6 \%)$ case, 1500 $<2500$ grams' body weight neonates were found in 9 $(14.8 \%)$ and more than or equal to 2500 grams' body weight neonates were found in $51(83.6 \%)$ cases. The difference was statistically significant $(\mathrm{p}=0.002)$ [Table4]. Among 39 patients in sepsis group rupture of membranes $>18$ hours was found in $27(69.2 \%)$ cases and absent in $12(30.8 \%)$ cases. Among 61 patients in non-sepsis group rupture of membranes $>18$ hours was found in $27(44.3 \%)$ cases and absent in 34 (55.7\%) cases. The difference was statistically significant $(\mathrm{p}=0.015)$ [Table-5]. Among 39 patients in sepsis group single unclean or $>3$ sterile vaginal examinations during labor was found in $11(28.2 \%)$ cases and absent in $28(71.8 \%)$ cases. Among 61 patients in nonsepsis group prolonged labor was found in $4(6.6 \%)$ cases and absent in $57(93.4 \%)$ cases. The difference was statistically significant $(\mathrm{p}=0.003)$ [Table-6]. Among 39 patients in sepsis group positive blood culture was found in $9(23.1 \%)$ cases and negative in 30 (76.9\%) cases. Among 61 patients in non-sepsis group positive blood culture was not found and negative all in 
$61(100.0 \%)$ cases [Table-7]. The difference was statistically significant $(\mathrm{p}=0.001)$. (Table-1). The mean Total leukocyte count was found in $10.92 \times 10^{9} \pm 7.89$ $\mathrm{x} 10^{9}$ and $12.88 \times 10^{9} \pm 5.88 \times 10^{9}$ in sepsis and nonsepsis group respectively. The difference was not statistically significant $(\mathrm{p}=0.160)$. The mean $\mathrm{I} / \mathrm{T}$ ration was found in $0.27 \pm 0.07$ and $0.15 \pm 0.05$ in sepsis and non-sepsis group respectively. The difference was statistically significant $(\mathrm{p}=0.001)$. The mean $\mathrm{C}$-reactive protein was found in $18.38 \pm 10.11$ and $2.71 \pm 1.68$ in sepsis and non-sepsis group respectively. The difference was statistically significant $(p=0.001)$. The mean Absolute neutrophil count was found in $4226.9 \pm$ 2370.7 and $5210.0 \pm 1297.6$ in sepsis and non-sepsis group respectively. The difference was statistically significant $(\mathrm{p}=0.009)$ [Table-8].

Table-1: Distribution of patient according to gestational age group $(n=100)$

\begin{tabular}{|c|c|c|c|}
\hline Gestational Age & \multicolumn{2}{|c|}{ Group } & \multirow{2}{*}{ P Value } \\
\cline { 2 - 3 } & Sepsis & Non-sepsis & \\
\hline$<37$ & $14(35.9)$ & $8(13.1)$ & 0.001 \\
\hline$\geq 37$ & $25(64.1)$ & $53(86.9)$ & \\
\hline
\end{tabular}

Table-2: Distribution of neonates according to the sex $(n=100)$

\begin{tabular}{|c|c|c|c|}
\hline \multirow{2}{*}{ Sex } & \multicolumn{2}{|c|}{ Group } & \multirow{2}{*}{ P Value } \\
\cline { 2 - 3 } & Sepsis & Non-sepsis & \\
\hline Male & $20(51.3)$ & $42(68.9)$ & 0.013 \\
\hline Female & $19(48.7)$ & $19(31.1)$ & \\
\hline
\end{tabular}

Table-3: Distribution of patient according to Apgar score $(\mathbf{n}=100)$

\begin{tabular}{|c|c|c|c|}
\hline \multirow{2}{*}{ APGAR Score } & \multicolumn{2}{|c|}{ Group } & \multirow{2}{*}{ P Value } \\
\cline { 2 - 3 } & Sepsis & Non-sepsis & \\
\hline$<4$ & $7(17.9)$ & $3(4.9)$ & 0.034 \\
\hline$\geq 4$ & $32(82.1)$ & $58(95.1)$ & \\
\hline
\end{tabular}

Table-4: Distribution of patient according to birth weight group $(n=100)$

\begin{tabular}{|c|c|c|c|}
\hline \multirow{2}{*}{ Birth weight $(\mathbf{g m})$} & \multicolumn{2}{|c|}{ Group } & \multirow{2}{*}{ P Value } \\
\cline { 2 - 3 } & Sepsis & Non-sepsis & \\
\hline$<1500$ & $3(7.7)$ & $1(1.6)$ & \multirow{2}{*}{0.002} \\
\hline $1500-<2500$ & $16(41.0)$ & $9(14.8)$ & \\
\hline$\geq 2500$ & $20(51.3)$ & $51(83.6)$ & \\
\hline
\end{tabular}

Table-5: Distribution of patient according to rupture of membranes $>18$ hours

\begin{tabular}{|c|c|c|l|}
\hline \multirow{2}{*}{ Factor } & \multicolumn{2}{|c|}{ Group } & \multirow{2}{*}{ P Value } \\
\cline { 2 - 4 } & Sepsis & Non-sepsis & \\
\hline Present & $27(69.2)$ & $12(30.8)$ & \multirow{2}{*}{0.015} \\
\hline Absent & $27(44.3)$ & $34(55.7)$ & \\
\hline
\end{tabular}

Table-6: Distribution of patient according to single unclean or $>3$ sterile vaginal examinations during labor

\begin{tabular}{|c|c|c|c|}
\hline \multirow{2}{*}{ Single unclean } & \multicolumn{2}{|c|}{ Group } & \multirow{2}{*}{ P Value } \\
\cline { 2 - 3 } & Sepsis & Non-sepsis & \\
\hline Yes & $11(28.2)$ & $4(6.6)$ & \multirow{2}{*}{0.003} \\
\hline No & $28(71.8)$ & $57(93.4)$ & \\
\hline
\end{tabular}

Table-7: Distribution of patient according to blood culture $(n=100)$

\begin{tabular}{|c|c|c|c|}
\hline \multirow{2}{*}{ Blood culture } & \multicolumn{2}{|c|}{ Group } & \multirow{2}{*}{ P Value } \\
\cline { 2 - 3 } & Sepsis & Non-sepsis & \\
\hline Positive & $9(23.1)$ & $0(0.0)$ & \multirow{2}{*}{0.001} \\
\hline Negative & $30(76.9)$ & $61(100.0)$ & \\
\hline
\end{tabular}


Table-8: Distribution of findings in different investigations $(n=100)$

\begin{tabular}{|c|c|c|c|}
\hline \multirow{2}{*}{ Component } & \multicolumn{2}{|c|}{ Group } & \\
\cline { 2 - 4 } & Sepsis Mean \pm SD & Non-sepsis Mean \pm SD & P value \\
\hline Total leukocyte count & $10.92 \times 10^{9} \pm 7.89 \times 10^{9}$ & $12.88 \times 10^{9} \pm 5.88 \times 10^{9}$ & 0.16 \\
\hline I/T ration & $0.27 \pm 0.07$ & $0.15 \pm 0.05$ & 0.001 \\
\hline Absolute neutrophil count & $4226.9 \pm 2370.7$ & $5210.0 \pm 1297.6$ & 0.009 \\
\hline C-reactive protein & $18.38 \pm 10.11$ & $2.71 \pm 1.68$ & 0.001 \\
\hline
\end{tabular}

\section{DisCUSSION}

A total number of 100 patients were enrolled in this study and was categorized into two groups. One was sepsis group which was taken as case and another group was the non-sepsis group which was taken as control. The distribution of neonates according to sex was recorded. Among 39 patients in sepsis group gestational age less than 37 weeks was found in 14 $(35.9 \%)$ cases and more than or equal to 37 weeks in $25(64.1 \%)$ cases. Among 61 patients in non-sepsis group gestational age less than 37 weeks was found in 8 $(13.1 \%)$ cases and more than or equal to 37 weeks in 53 $(86.9 \%)$ cases. The difference was statistically significant $(\mathrm{p}=0.001)$. In sepsis group male and female were in $20(51.3 \%)$ cases and $19(48.7 \%)$ cases respectively. In non-sepsis group male and female were in $42(68.9 \%)$ cases and $19(31.1 \%)$ cases respectively. The difference was statistically significant $(\mathrm{p}=0.013)$. Less than 4 Apgar score was found in 7 (17.9\%) cases and $3(4.9 \%)$ cases in sepsis and non-sepsis groups respectively. More than or equal to 4 Apgar score was found in $32(82.1 \%)$ cases and $58(95.1 \%)$ cases in sepsis and non-sepsis groups respectively. The difference was statistically significant ( $\mathrm{p}=0.034)$. Similar result was reported by Yancey et al. and mentioned that Apgar score was one of the risk factor for neonatal sepsis [11]. Schuchat et al. and Thomas et al. had reported similar findings $[12,13]$

In sepsis group less than $<1500$ grams' body weight neonates were found in $3(7.7 \%)$ case, 1500$<2500$ grams' body weight neonates were found in 16 $(41.0 \%)$ and more than or equal to 2500 grams' body weight neonates were found in $20(51.3 \%)$ cases. In non-sepsis group less than $<1500$ grams' body weight neonates were found in $1(1.6 \%)$ case, $1500-<2500$ grams' body weight neonates were found in 9 (14.8\%) and more than or equal to 2500 grams' body weight neonates were found in $51(83.6 \%)$ cases. The difference was statistically significant $(p=0.002)$. Similar result was reported by Yancey et al. and mentioned that birth weight was association with neonatal sepsis [10]. The reason might be due to the more chance of neonatal infection as because low birth weight neonates had lack of immunity. Adair et al. had reported that low birth weight of the neonate was one of the risk factor for the causation of neonatal sepsis which was consistent with the present study [14].

The distribution of patient according to rupture of membranes >18 hours was recorded. Among 39 patents in sepsis group rupture of membranes $>18$ hours was found in $69.2 \%$ cases and absent in $30.8 \%$ cases. Among 61 patients in non-sepsis group rupture of membranes $>18$ hours was found in $44.3 \%$ cases and absent in $55.7 \%$ cases. The difference was statistically significant $(\mathrm{p}=0.015)$. Similar result was reported by Yancey et al. [11] and mentioned that rupture of membranes $>18$ hours was the risk factor of neonatal sepsis. Adair et al. [14] and Thomas et al. [13] had reported that rupture of the membrane was one of the risk factor for the causation of neonatal sepsis which was consistent with the present study. Schuchat et al. [12] and Seaward et al. [17] had also found a similar result. The reason of this might be due to the long time rupture of the membrane allows to enter the organisms in to the neonates during delivery.

Among 39 patients in sepsis group single unclean or $>3$ sterile vaginal examinations during labor was found in $11(28.2 \%)$ cases and absent in $28(71.8 \%)$ cases. Among 61 patients in non-sepsis group prolonged labor was found in $4(6.6 \%)$ cases and absent in $57(93.4 \%)$ cases. The difference was statistically significant $(p=0.003)$. The difference was statistically significant $(\mathrm{p}=0.003)$. Similar result was reported by Yancey et al. (1996) and mentioned that single unclean or unsterile vaginal examination during labour was one of the risk factor for the causation of neonatal sepsis [11]. Thomas et al. was also reported the similar result [13]. Bhutta et al. had also found an association with frequent vaginal exams with amnionitis, early-onset sepsis, and neonatal infections [15]. Seaward et al. had also found a similar result [16]. Oddie and Embleton also reported that the single unclean or unsterile vaginal examination during labour related with maternal risk factors was also responsible for neonatal sepsis which was consistent with the present study [17].

The distribution of findings in different investigations was recorded. The mean Total leukocyte count was found in $10.74 \times 10^{9} \pm 8.63 \times 10^{9}$ and 12.01 
$\mathrm{x} 10^{9} \pm 4.58 \times 10^{9}$ in sepsis and non-sepsis group respectively. The mean $\mathrm{I} / \mathrm{T}$ ration was found in $0.26 \pm$ 0.06 and $0.15 \pm 0.03$ in sepsis and non-sepsis group respectively. The mean $\mathrm{C}$-reactive protein was found in $17.57 \pm 8.39$ and $2.58 \pm 1.41$ in sepsis and non-sepsis group respectively. The mean Absolute neutrophil count was found in $3661.5 \pm 2737.50$ and $4955.0 \pm 1290.01$ in sepsis and non-sepsis group respectively. Similar result was reported by Shitaye and mentioned that these markers are highly sensitive and specific and can be used for routine clinical work-up in community health delivery systems, particularly in developing countries [18]. Various hematological parameters, a complete blood count, WBC count and differential and absolute neutrophil count had been evaluated for their ability to predict neonatal sepsis [19]. An increased I: T ratio of $>0.2$ had been reported to have moderately increased specificity for sepsis [19]. This result was consistent with the present study.

\section{Limitations of the study}

Our study wasn't a blinded study so patient bias was present along with observer bias in subjective recording and the small sample size was taken in this study. It was a non-randomized sampling method. It was a single cantered study and the study and follow up period was short in comparable to other series.

\section{CONCLUSION AND \\ RECOMMENDATIONS}

In conclusion, the findings of this study permit to conclude that different maternal and neonatal risk factors are responsible for neonatal sepsis of which prematurity, low birth weight, low apgar score, maternal febrile illness, frequent vaginal examinations and maternal rupture of amniotic membranes $>18$ hours are significantly associated with neonatal sepsis.

\section{REFERENCES}

1. Tripathi, S., \& Malik, G. K. (2010). Neonatal Sepsis: past, present and future; a review article. Internet Journal of Medical UpdateEJOURNAL, 5(2).

2. Vergnano, S., Sharland, M., Kazembe, P., Mwansambo, C., \& Heath, P. T. (2005). Neonatal sepsis: an international perspective. Archives of Disease in Childhood-Fetal and Neonatal Edition, 90(3), F220-FF224.

3. Bang, A. T., Bang, R. A., Baitule, S. B., Reddy, M. H., \& Deshmukh, M. D. (1999). Effect of homebased neonatal care and management of sepsis on neonatal mortality: field trial in rural India. The lancet, 354(9194), 1955-1961.
4. Stoll, B. J., Hansen, N., Fanaroff, A. A., Wright, L. L., Carlo, W. A., Ehrenkranz, R. A., ... \& Poole, W. K. (2002). Late-onset sepsis in very low birth weight neonates: the experience of the NICHD Neonatal Research Network. Pediatrics, 110(2), 285-291.

5. Airede, A., Lim, N. L., Wong, Y. H., Boo, N. Y., Kasim, M. S., \& Chor, C. Y. (1995). Bacteraemic infections in a neonatal intensive care unit: a nine months survey. Med J Malaysia, 50(1), 59-63.

6. WHO Young Infants Study Group. (1999). Clinical prediction of serious bacterial infections in young infants in developing countries. The Pediatric Infectious Disease Journal, 18(10), S23-S31.

7. Moreno, M. T., Vargas, S., Poveda, R., \& SáezLlorens, X. (1994). Neonatal sepsis and meningitis in a developing Latin American country. The Pediatric infectious disease journal,13(6), 516520.

8. Heath, P. T., Yusoff, N. N., \& Baker, C. J. (2003). Neonatal meningitis. Archives of disease in childhood-Fetal and neonatal edition, 88(3), F173F178.

9. Vesikari, T., Janas, M., Grönroos, P., Tuppurainen, N., Renlund, M., Kero, P., ... \& Nyman, R. (1985). Neonatal septicaemia. Archives of disease in childhood, 60(6), 542-546.

Bang, A. T., Reddy, H. M., Deshmukh, M. D., Baitule, S. B., \& Bang, R. A. (2005). Neonatal and infant mortality in the ten years (1993 to 2003) of the Gadchiroli field trial: effect of home-based neonatal care. Journal of perinatology, 25(1), S92S107. :S92-107

10. Yancey, M. K., Duff, P., Kubilis, P., Clark, P., \& Frentzen, B. H. (1996). Risk factors for neonatal sepsis. Obstetrics \& Gynecology, 87(2), 188-194.

11. Schuchat, A., Zywicki, S. S., Dinsmoor, M. J., Mercer, B., Romaguera, J., O'Sullivan, M. J., ... \& Levine, O. S. (2000). Risk factors and opportunities for prevention of early-onset neonatal sepsis: a multicenter case-control study. Pediatrics, 105(1), 21-26.

12. Newman, T. B., Puopolo, K. M., Wi, S., Draper, D., \& Escobar, G. J. (2010). Interpreting complete blood counts soon after birth in newborns at risk for sepsis. Pediatrics, 126(5), 903-909.

13. Adair, C. E., Kowalsky, L., Quon, H., Ma, D., Stoffman, J., McGeer, A., ... \& Davies, H. D. (2003). Risk factors for early-onset group B streptococcal disease in neonates: a populationbased case-control study. Cmaj, 169(3), 198-203.

14. BHUTTA, Z. A., NAQVI, S. H., MUZAFFAR, T., \& FAROOQUI, B. J. (1991). Neonatal sepsis in 
Pakistan: Presentation and pathogens. Acta Padiatrica, 80(6-7), 596-601.

15. Oddie, S., \& Embleton, N. D. (2002). Risk factors for early onset neonatal group B streptococcal sepsis: case-control study. Bmj, 325(7359), 308.

16. Seaward, P. G. R., Hannah, M. E., Myhr, T. L., Farine, D., Ohlsson, A., Wang, E. E., \& Term PROM Study Group. (1998). International multicenter term PROM study: evaluation of predictors of neonatal infection in infants born to patients with premature rupture of membranes at term. American journal of obstetrics and gynecology, 179(3), 635-639.

17. Shitaye, D. (2008). Neonatal Sepsis: Bacterial etiologic agents and their antibiotic succeptibility pattern in Tikur Anbessa University Hospital, Addis Ababa, Ethiopia. Addis Ababa University, Addis Ababa, Ethiopia.

18. Manucha, V., Rusia, U., Sikka, M., Faridi, M. M. A., \& Madan, N. (2002). Utility of haematological parameters and C-reactive protein in the detection of neonatal sepsis. Journal of paediatrics and child health, 38(5), 459-464.

Cite This Article: Debabrata Roy et al (2021). Association of Maternal and Neonatal Risk Factors with Early Onset Neonatal Sepsis. East African Scholars J Med Sci, 4(3), 78-83. 